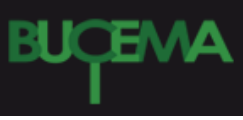

Bulletin du centre d'études médiévales d'Auxerre | BUCEMA

Hors-série $n^{\circ} 10 \mid 2016$

L'origine des sites monastiques : confrontation entre la terminologie des sources textuelles et les données archéologiques

\title{
Les origines de l'abbaye lyonnaise Saint-Martin de Savigny
}

Olivia Puel et Pierre Ganivet

\section{QpenEdition \\ Journals}

Édition électronique

URL : https://journals.openedition.org/cem/14491

DOI : $10.4000 /$ cem. 14491

ISSN : 1954-3093

Éditeur

Centre d'études médiévales Saint-Germain d'Auxerre

Référence électronique

Olivia Puel et Pierre Ganivet, « Les origines de l'abbaye lyonnaise Saint-Martin de Savigny », Bulletin du centre d'études médiévales d'Auxerre / BUCEMA [En ligne], Hors-série n 10 | 2016, mis en ligne le 09 décembre 2016, consulté le 04 mars 2023. URL : http://journals.openedition.org/cem/14491 ; DOI : https://doi.org/10.4000/cem.14491

Ce document a été généré automatiquement le 4 mars 2023

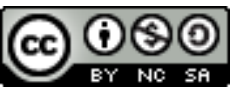

Creative Commons - Attribution - Pas d'Utilisation Commerciale - Partage dans les Mêmes Conditions 4.0 International - CC BY-NC-SA 4.0

https://creativecommons.org/licenses/by-nc-sa/4.0/ 


\title{
Les origines de l'abbaye lyonnaise Saint-Martin de Savigny
}

\author{
Olivia Puel et Pierre Ganivet
}

\section{Introduction}

1 À l'époque romane, Savigny est une abbaye majeure du diocèse de Lyon : fondée sur de précieux soutiens et sur une assise foncière solide, sa puissance s'exprime à la fois par une influence incontestable dans les jeux politiques régionaux ${ }^{1}$, par un rayonnement dépassant largement l'aire du Lyonnais ${ }^{2}$, mais aussi par une architecture monumentale profondément renouvelée au $\mathrm{XI}^{\mathrm{e}}$ siècle $^{3}$. Ces dernières années, la connaissance de cet établissement lyonnais a profité de travaux collectifs et individuels, qui devraient, à terme, aboutir à des publications ${ }^{4}$. Ses origines restent néanmoins largement ignorées en raison de l'absence de toute documentation, de quelque nature qu'elle soit, contemporaine de la fondation.

2 Un probable incendie, survenu dans les années 930-940, lors d'un épisode hongrois qu'il faut aujourd'hui considérer à sa juste mesure ${ }^{5}$, explique le vide documentaire auquel ont été confrontés tous les historiens et, avant eux, tous les moines qui se sont intéressés à cette question. Le Liber cartarum de l'abbé Ponce, rédigé vers 1135 et publié sous le nom de Cartulaire de Savigny ${ }^{6}$ en 1853 , témoigne déjà de cet oubli des origines. En outre, le caractère ponctuel des opérations archéologiques menées, au gré des opportunités, dans le cadre d'une thèse d'archéologie médiévale, interdit toute vision générale du site avant l'installation de l'abbaye. Quelques artefacts pourraient témoigner d'une occupation antique si tant est que leur provenance soit assurée : or, la stèle (CIL XIII, 1663) scellée dans la façade d'une maison est dépourvue de tout contexte archéologique $^{7}$ et les rares tessons de sigillée appartiennent aux niveaux de remblais rapportés au moment de la construction de l'abbatiale romane, à l'emplacement du chevet $^{8}$. Au XIX ${ }^{e}$ siècle, cette absence de données directes n'a évidemment pas manqué d'alimenter quelques légendes érudites ${ }^{9}$, rapidement démenties par l'éditeur du cartulaire, Auguste Bernard ${ }^{10}$. 
3 Nos travaux récents ont cependant permis de mettre au jour quelques indices, qui, certes, n'apportent pas de réponses définitives, loin s'en faut, mais qui permettent quand même de suggérer de nouvelles pistes de réflexion. Cette journée d'études, organisée dans le cadre du PCR sur les Monastères d'Europe occidentale, offre l'occasion de rouvrir le dossier de la fondation de l'abbaye de Savigny en s'intéressant successivement à l'historiographie monastique des origines et aux preuves de son existence dès l'époque carolingienne, puis aux indices tangibles et convergents qui suggèrent l'existence, sur le site même de son implantation, d'un établissement majeur, antérieur à l'abbaye elle-même.

\section{Historiographie savinienne des origines}

4 Dans les archives saviniennes, largement exploitées lors de nos travaux collectifs, ont été mises au jour trois versions radicalement différentes des origines de l'abbaye de Savigny : elles permettent de retracer une évolution marquée de la pensée monastique, mais aussi de s'interroger sur les raisons, qui, à des époques diverses, ont poussé les moines à élaborer leur propre version de l'histoire.

\section{À la recherche d'une légitimité au XII siècle}

$5 \quad \mathrm{Au}$ XII ${ }^{\mathrm{e}}$ siècle, l'abbaye de Savigny est au faîte de sa puissance politique et économique ; elle compte désormais parmi les seigneurs les plus influents de la région, aux côtés de l'Église de Lyon, du comté de Forez et de la sirerie de Beaujeu. Le réseau de ses dépendances forme un contingent homogène dans les monts du Lyonnais, mais s'étend aussi dans des diocèses plus lointains, comme ceux de Saintes, de Die ou de Genève. Le nouveau chevet de l'église Saint-Martin est déjà construit et, malgré le caractère hybride provoqué par son raccordement provisoire à l'ancienne nef ${ }^{11}$, l'édifice affiche selon toute vraisemblance une monumentalité inédite. Dans ce contexte-là, la rédaction du Liber cartarum, qui intervient vers 1135 à l'initiative de l'abbé Ponce de Lay, témoigne, lui aussi, de la vitalité savinienne en ce sens où les moines disposent des moyens nécessaires pour préserver leur patrimoine commun.

Or, ce document historique reste muet sur les origines de l'abbaye. Le prologue évoque simplement son ancienneté, sans plus de précisions : Sapiniacense coenobium olim longe $a b$ antiquis patribus instructum $(. . .)^{12}$. Ce silence presque surprenant s'explique aussi bien par un manque réel de documentation que par une volonté délibérée et réfléchie de s'intéresser à la restauration du $\mathrm{x}^{\mathrm{e}}$ siècle plutôt qu'à la fondation de l'abbaye. Le cartulariste procède d'ailleurs à une relecture patente des événements survenus au cours du siècle de l'an Mil. Il impute d'abord aux Hongrois la désolation du monastère, qui semble pourtant résulter de désordres internes. Parmi les deux artisans du redressement de l'abbaye, il choisit ensuite de mettre en valeur la figure de Gausmar (954-984) plutôt que celle de son prédécesseur, Badin (v. 936-v. 955). De fait, Gausmar est pour lui l'abbé-pèlerin, celui qui se rend à Jérusalem pour doter son église de reliques, mais aussi l'abbé-saint, celui qui donne la parole à un muet venu se recueillir sur son tombeau. Au contraire, Badin n'est pour lui que le premier abbé qu'il a réussi à identifier après le raid hongrois. Dans les sources contemporaines, ou presque, des événements supposés, c'est pourtant Badin qui apparaît comme un personnage clé de la réforme savinienne: en 949-950, il parvient à obtenir de l'archevêque Bourchard I 
(948-954) un privilège de libre élection abbatiale. La préférence des moines pour Gausmar ne peut relever du hasard ${ }^{13}$.

7 Badin est le restaurateur de Savigny, un restaurateur qui pourrait d'ailleurs avoir été envoyé par Odon lui-même si son origine clunisienne se révélait exacte. Au cours de son abbatiat, il parvient à redresser le monastère alors plongé dans une situation critique depuis un temps sans doute relativement long. À son entrée en charge, Gausmar hérite logiquement d'une situation bien meilleure qui lui permet de s'attaquer à une autre mission d'envergure : la quête des reliques. En allant chercher les restes insignes de saints prestigieux, à Jérusalem notamment, il dote ainsi l'abbaye de Savigny d'« ancêtres protecteurs ", ceux-là même, qui, d'après Patrick Geary, sont susceptibles de défier la concurrence d'autres maisons ecclésiastiques ou de s'opposer à la malveillance de certains laïcs ${ }^{14}$. En cette fin du $\mathrm{x}^{\mathrm{e}}$ siècle, alors que le monastère vient de surmonter ce qui est sans doute la première crise importante de son histoire, Gausmar s'offre par cette action d'éclat le statut d'un re-fondateur, d'un personnage capable d'assurer à la communauté monastique un succès durable.

8 À la suite d'un miracle survenu sur sa tombe, originellement placée dans la chapelle Saint-Léger, Gausmar est d'ailleurs promu au rang de saint par les moines et sa dépouille est déplacée dans un caveau en élévation, installé cette fois dans l'une des nouvelles chapelles orientales de l'église Saint-Martin. La date du miracle est comprise entre 984, année de la mort de Gausmar, et le premier tiers du XII ${ }^{\mathrm{e}}$ siècle, époque à laquelle le cartulariste mentionne cet événement, sans donner le moindre détail. En revanche, la date de la sanctification de l'abbé et de la translation de sa dépouille n'est, à vrai dire, pas connue avec précision. Elle se situe dans une fourchette large, qui va jusqu'à la fin du Moyen Âge, époque à laquelle un grand-prieur, Benoît Maillard, relate le miracle avec davantage de développements. Il est cependant très tentant de la situer dans ce XII siècle triomphant : c'est alors d'un saint homme - pas d'un réformateur dont l'abbaye a besoin pour légitimer sa puissance dans un diocèse dominé par l'archevêque de Lyon. Le transfert du corps de Gausmar prend tout son sens dès lors que cet abbé est "officiellement» désigné comme la figure emblématique du monachisme savinien. L'histoire écrite dans le Liber cartarum est traduite dans l'architecture de la nouvelle église ; elle procède d'un même schéma de pensée, que les moines cherchent à ancrer dans la mémoire collective.

\section{La promotion de la réforme à la fin du $\mathrm{XV}^{\mathrm{e}}$ siècle}

9 À une époque où l'abbé ne réside plus à l'abbaye, mais au château de Sain-Bel, le grandprieur acquiert une importance considérable au sein du couvent. Benoît Mailliard, qui accède à cette dignité dans les dernières décennies $d u \mathrm{xv}^{\mathrm{e}}$ siècle, joue ainsi un rôle fondamental dans l'élaboration de la réforme souhaitée, dès son entrée en charge, par l'abbé François I d'Albon (1492-1521). Notons que cette initiative suit de peu la restauration entreprise à Cluny par Jean de Bourbon (1466-1480/1485) ${ }^{15}$. S'il est difficile de juger la portée de cette restauration spirituelle, il faut néanmoins nuancer la tradition historiographique $\mathrm{du} \mathrm{xIX}^{\mathrm{e}}$ siècle, qui confère trop systématiquement aux moines de la fin du Moyen Âge des mœurs détestables ${ }^{16}$. Dans ses multiples écrits, Benoît Mailliard rappelle les principes de la vie régulière et le bon déroulement des cérémonies religieuses, mais il cherche aussi à ancrer dans la mémoire collective le souvenir des hommes importants pour l'histoire de l'abbaye de Savigny. En compilant 
les archives du monastère et en réalisant une chronique sous forme d'épitomé du cartulaire, en réactualisant les manuscrits liturgiques de Guillaume Bollat (xIII ${ }^{\mathrm{e}}$ siècle) ou de Philippe Morel (v. 1390), en décrivant les édifices ou les épitaphes qu'il a sous les yeux, il fait véritablement œuvre d'historien.

Benoît Mailliard se prononce évidemment sur la question des origines : il perpétue d'abord, logiquement, la mémoire de l'abbé Gausmar, en relatant dans le détail son miracle thaumaturge ${ }^{17}$. Mais il cherche aussi à pallier les lacunes documentaires en se prononçant en faveur d'une fondation carolingienne, d'une part, et en louant la restauration de l'abbé Badin, d'autre part. Il met en scène Charlemagne lui-même dans le rôle principal du fondateur. Citant une charte de l'abbé Adalbert, il se fonde sur une série de déductions pour le moins contestables pour prouver ses allégations :

Et primo sciendum est quod tempore Caroli magni fuit hoc nostrum Savigniacense monasterium primitus fondatum sed per que $[\mathrm{m}]$ certive ignorantes tenemus tam generaliter quam per Carolum magnum fundatum fuit. (...) ex eo quia ut dictum est fuit tempore ipsius Caroli magni regis Francie huius modi monasterium fundatum quia ipse Carolus ad huic Sancti Martini fondavit tercio quia primus huius monasterii abbas qui vocabatur Adalbertus tempore Caroli magni fuit ut Poncius abbas prestaria per dictum Adalbertum facta in libro suo cartarum attestatur ${ }^{18}$.

11 Si le monastère existait du temps de Charlemagne, si Adalbert, le premier abbé de Savigny, a vécu à la même époque, si Charlemagne a fondé un monastère Saint-Martin, alors Charlemagne peut être considéré comme le fondateur de l'abbaye de Savigny. Or, Adalbert n'est que le premier abbé connu du cartulariste ; il n'a pas vécu à l'époque de Charlemagne, mais à celle de Carloman. Si prestigieux soit-il, le choix impérial relève clairement de l'affabulation.

En outre, Benoît Mailliard redonne à Badin une place de choix dans l'historiographie des origines, en le mentionnant comme le restaurateur de l'abbaye, mais aussi comme un sanctus et justus abbas ${ }^{19}$. Cherche-t-il, par ces qualificatifs élogieux, à rétablir une certaine équité entre Badin et Gausmar sans pour autant nuire à l'image de ce dernier ? Qu'importe! Ce qu'il faut souligner à ce stade, c'est le souci constant qu'a l'auteur de croiser les sources, avec rigueur, pour démêler les faits historiques et pour proposer une nouvelle histoire du monastère. L'attribution de la fondation à Charlemagne n'est pas une approximation, encore moins une erreur; il s'agit plutôt d'un raccourci arrangeant qui lui permet non seulement d'offrir à Savigny des origines prestigieuses, mais aussi de mettre en avant l'idée de restauration spirituelle. Benoît Mailliard connaît Charlemagne pour sa quête des origines, en particulier dans le domaine religieux; il n'ignore pas non plus le rôle qu'a joué Badin dans le redressement de l'abbaye au $\mathrm{x}^{\mathrm{e}}$ siècle - le privilège de Bourchard était conservé dans les archives du monastère. Charlemagne et Badin sont, à des échelons différents, des hommes de réforme ; François I d'Albon et Benoît Mailliard aspirent sans doute à être reconnus comme tels. Dès lors, le choix de lier les origines saviniennes à ces deux personnages illustres ne pourrait-il pas s'expliquer par la volonté de légitimer la réforme spirituelle et matérielle mise en œuvre par François I d'Albon?

\section{La solitude comme preuve d'ancienneté au XVIII siècle}

13 Alors que bon nombre d'établissements ecclésiastiques ont été sécularisés à l'époque moderne, l'abbaye de Savigny perdure jusqu'à l'aube de la Révolution française. Elle connaît un $\mathrm{XVIII}^{\mathrm{e}}$ siècle morose : les moines éprouvent de grandes difficultés pour 
recruter les vingt frères prévus par l'ordonnance archiépiscopale de Camille de Neufville (1653-1693 $)^{20}$, mais ils restent malgré tout scrupuleusement attachés aux cinq preuves de noblesse demandées à chaque postulant. Ils se heurtent surtout à l'exigence et à la mauvaise volonté d'abbés commendataires pour qui leur monastère lyonnais n'est qu'un bénéfice parmi les autres. Nombreux sont alors les conflits qui opposent ouvertement le grand-prieur et le convent à Jean de Fuligny Damas (1711-1761) ou à François de Clugny (1761-1781). C'est dans ce contexte troublé que, le 16 octobre 1766, Laurent de Foudras, grand-prieur, adresse au nom de ses moines une demande de sécularisation aux commissaires chargés de statuer sur le sort du monastère. Il écrit alors un historique qui insiste sur la question des origines en reprenant une légende de fondation rapportée, si ce n'est créée, par François de Fournillon Butery au début du XVIII ${ }^{\mathrm{e}}$ siècle, puis véhiculée par les auteurs de Gallia christiana ${ }^{21}$.

Histoire de François de Fournillon Butery (1718) :

"Il est difficile de bien établir le temps de la fondation. Si on en veut croire une encienne tradition, elle est entre le cinquième et le sixième siècle de l'Église. On prétend que six solitaires retirés dans une espèce de dézert, nommé enciennement locus Sapiniacensis, étant informés que saint Maur, diciple de saint Benoit, passoit a l'Arbresle au tems qu'il fut envoyé dans les Gaules, profitèrent de l'occasion et du voisinage de son passage et luy furent demander l'habit de saint Benoit que ce saint leur accorda. Il reste dans l'abbay[e] un monumant sensible de cette tradition. C'est une petite chapelle massive soub le tiltre de saint Légier, qui est un peu séparée des églises et lieux réguliers de cette abbaye, et ou ces solitaires fesoient leurs prières. Cette chapelle a résisté a touttes les injures des tems et les curieux qui l'on veû avouënt que la construction est des premiers siècles. »

Tableau de Laurent de Foudras (1766) :

«L'abbaye de St-Martin de Savigny alias Sapini, diocèse de Lyon, située à quatre lieux de cette ville, dans une solitude telle que les saints Pères vouloient l'établissement des maisons religieuses, éloignées du tumulte des villes, paroit être $\mathrm{du}$ sixième siècle. La tradition rapporte que cette solitude fut en premier lieu habitée par des solitaires qui faisoient leurs exercices dans une petite chapelle souterraine qui existe encore, joignant la chapelle de Notre-Dame (dont on parlera ensuite), et que lorsque saint Maur vint en France pour y établir la règle de SaintBenoît, ces solitaires en embrassèrent la règle. Dans le huitième siècle, Charlemagne en fut le restaurateur. Il y fit et donna beaucoup de biens. Plusieurs autres souverains et nobles s'empressèrent aussi de suivre ses traces et d'y placer des sujets que la sainteté des abbés et religieux y attiroient. »

16 Très proches l'un de l'autre, ces deux textes procèdent avec évidence de la même tradition historiographique. Charlemagne n'est plus le fondateur de l'abbaye, mais un simple restaurateur. Saint Maur lui-même aurait donné aux premiers moines saviniens la règle bénédictine, conférant ainsi au monastère des origines bien plus anciennes que l'époque carolingienne. C'est justement cette ancienneté qui est recherchée par Laurent de Foudras pour justifier le maintien d'un chapitre à Savigny. Tout son raisonnement repose sur cet argument-là : quelle autre maison peut se prévaloir, comme Savigny, d'origines antiques et illustres propres à accueillir les fils cadets des nobles familles lyonnaises?

17 Par sa mention des Pères de l'Église, de la « solitude » et des " premiers solitaires » ou de la chapelle souterraine originelle, le texte se rattache en effet à un courant de pensée qui prévaut chez les bénédictins de Saint-Maur. Contemporain, ou presque, de François de Fournillon Butery, le mauriste Jean Mabillon prône, en effet, dans la seconde moitié du XVII ${ }^{e}$ siècle, un retour aux origines du monachisme même, en se 
référant notamment à l'exemple du Mont-Cassin. Il théorise le mouvement de réforme qui a permis à sa congrégation de connaître un succès grandissant face aux ordres traditionnels, en proie à de nombreuses difficultés. Il n'y a donc rien d'étonnant à ce que François de Fournillon Butery puis Laurent de Foudras négligent Charlemagne, qui n'est plus qu'un "second fondateur ", et privilégient saint Maur, symbole du renouveau de la spiritualité monastique dans la France du XvIII ${ }^{e}$ siècle. Dans leur esprit, la solitude désigne un lieu éloigné des villes et des hommes, un lieu véritablement séparé du monde. Elle renvoie ainsi à la notion de "désert monastique ", qui tient plus du topos littéraire que d'une réalité empirique ${ }^{22}$. La chapelle Saint-Léger, à laquelle les deux textes font allusion, se prête alors parfaitement à cet idéal de solitude : petite, isolée, sombre, humide... En ce XviII ${ }^{\mathrm{e}}$ siècle finissant, elle cumule, en effet, les inconvénients qui permettent aux auteurs d'amplifier le mérite des premiers « solitaires » de l'abbaye.

\section{Le contexte de la fondation}

\section{Quelques jalons chronologiques} $\mathrm{IX}^{\mathrm{e}}$ siècle. Déjà exploitée par Michel Rubellin, dans le cadre de ses travaux sur les monastères lyonnais, la Notitia de servitio monasteriorum ${ }^{23}$ définit les devoirs des établissements monastiques de l'Empire envers l'empereur et le monasterium Saviniciaco (sic) qu'elle mentionne est identifié par tous les auteurs à Savigny. Ce document répartit les monastères en trois catégories, la première regroupant les établissements devant à la fois des dons (dona) et un service militaire (militia), la deuxième ceux, qui, exemptés de service armé, ne doivent que des dons, la troisième, enfin, les monastères dont l'unique charge consiste en des prières en faveur de l'empereur et de ses fils. Savigny relève de cette dernière catégorie, peut-être parce que le monastère, d'origine récente, est encore peu riche ${ }^{24}$. cartarum de Ponce ${ }^{25}$ est une précaire consentie par "Just, abbé de Saint-Martin de Savigny » : Ego Justus abbas sancti Martini Saviniacensis concedimus vobis illas res quae sunt in Sabonaco villa, quas Maifinus et uxor sua ad nostrum monasterium donaverunt... Elle semble être, à la réflexion, du 11 janvier 825 , même si un premier examen a pu amener d'autres conclusions ${ }^{26}$. Les biens alors concédés en précaire par l'abbé Just proviennent d'une donation nécessairement antérieure, mais impossible à dater : faut-il la vieillir d'une génération complète ou de quelques années seulement ? Ces biens sont en outre situés in Sabonaco villa: la correction de Sabonaco en Sabiniaco permettrait de situer à Savigny même cette opération foncière et de penser, par conséquent, que le patrimoine de Saint-Martin ne s'étendait guère au-delà de la villa sur laquelle le monastère pouvait être établi. L'hypothèse d'une fondation récente pourrait ainsi être confortée. Mais une telle correction, qui suppose une erreur sur le nom même du lieu d'implantation de l'abbaye, est d'autant plus difficile à justifier qu'une villa quae vocatur Savoniacus est attestée par ailleurs in agro Turiacensi ${ }^{27}$.

Ces textes prouvent que l'abbaye de Savigny existait au début du règne de Louis le Pieux et, peut-être, dès la fin du règne de Charlemagne. Il est malheureusement difficile d'aller au-delà de ce simple constat, même en s'appuyant sur d'autres sources historiques. L'absence de mention relative à Savigny dans le rapport envoyé par

Bulletin du centre d'études médiévales d'Auxerre | BUCEMA, Hors-série n 10 | 2016 
Leidrade à Charlemagne, en 810-811, implique-t-elle nécessairement que le monastère n'existait pas encore à cette époque ? Elle pourrait aussi s'expliquer par le simple fait que l'évêque de Lyon n'est pour rien dans sa fondation ou sa restauration ${ }^{28}$. Quant au patronage martinien du monastère, qui semble originel, il ne peut infirmer ni confirmer une fondation contemporaine de Charlemagne. Grégoire de Tours témoigne du succès du culte voué au saint confesseur dès le $\mathrm{VI}^{\mathrm{e}}$ siècle, et l'on sait que «cette faveur allait durer jusqu'au règne de Charlemagne puisque ce monarque, tout comme ses prédécesseurs de l'ancienne dynastie, avait une dévotion toute spéciale envers la cappa, insigne relique du saint »; on sait également que " par la suite, le culte de Martin ne connut pas l'irréversible déclin que l'on constate pour quelques autres ${ }^{29} »$. Aussi faut-il se contenter de remarquer, que, avec une datation dans le premier quart du $\mathrm{IX}^{\mathrm{e}}$ siècle, la fondation de Saint-Martin de Savigny pourrait s'inscrire dans un contexte local de renouveau monastique, dont la réforme de la vieille abbaye de l'île-Barbe par Benoît d'Aniane reste par ailleurs la meilleure illustration ${ }^{30}$. L'hypothèse d'une fondation impériale, chère à Benoît Mailliard, reste mal assurée dans la mesure où l'appartenance de Savigny au fisc impérial n'est pas démontrée. Il n'en reste pas moins que «l'abbaye fut considérée par les souverains carolingiens comme monastère royal $^{31}$ ", selon l'expression de Pierre-Roger Gaussin, et surtout qu'elle se trouvait, dans la première moitié $\mathrm{du} \mathrm{Ix}^{\mathrm{e}}$ siècle, "sous le patronage impérial", comme l'a déjà remarqué Michel Rubellin. La notitia de servitio monasteriorum recense, en effet, les établissements "sur lesquels le souverain exerçait une autorité plus ou moins directe $^{32}$ » et la tutelle impériale trouve confirmation dans le diplôme par lequel, en 852, Lothaire soumet à l'Église de Lyon « le monastère construit en l'honneur de notre Seigneur Jésus Christ, sous l'invocation du bienheureux Martin, évêque et confesseur, [monastère] qui est publiquement appelé Savigny, avec toutes ses dépendances ${ }^{33}$ ».

\section{Un établissement antérieur à l'abbaye?}

21 Révoquée en doute par nombre d'historiens de Savigny depuis Auguste Bernard, la tradition selon laquelle l'abbaye Saint-Martin aurait été fondée au milieu du $\mathrm{vl}^{\mathrm{e}}$ siècle, après la venue de saint Maur auprès d'un groupe d'ermites vivant dans cette partie des Monts du Lyonnais, alors couverts de forêts, a longtemps et largement alimenté la vision romantique des auteurs locaux, pour qui la fondation d'une communauté monastique a été le point de départ de vastes défrichements jusqu'à l'époque carolingienne. Tout, pourtant, de la géographie à la toponymie, dément l'idée de virginité du site et de la région dans l'Antiquité et au haut Moyen Âge.

La proximité du confluent de la Brévenne et de l'Azergues, de la voie d'Aquitaine et de l'aqueduc de la Brévenne fournit autant de raisons de penser que la région de Savigny a très tôt été occupée et mise en valeur. À Savigny même, si les traces d'occupation antique restent isolées et difficiles à interpréter, le toponyme ne peut guère dériver de silva, comme le voulaient d'anciens érudits, obligés de postuler un *Silvaniacus qui aurait fini par devenir Saviniacus ${ }^{34}$. Le nom de Savigny est une formation prédiale, le suffixe -acus accolé à l'anthroponyme romain Sabinus désignant un "domaine de Sabinus». À $10 \mathrm{~km}$ au nord-est, Fleurieux (Floriacus) paraît de même être un ancien "domaine de Florus»: les fouilles réalisées à l'occasion de la construction de l'autoroute A 89 ont d'ailleurs permis d'y découvrir un vaste établissement agricole du Haut-Empire $\left(\mathrm{I}^{\mathrm{er}}-\mathrm{III}{ }^{\mathrm{e}} \text { siècle }\right)^{35}$. La toponymie conserve de nombreux autres indices 
d'occupation tardo-antique et alti-médiévale aux environs de Savigny. Les lieux-dits Persanges et Marange, par exemple, sur le territoire actuel de la commune, semblent évocateurs d'une implantation germanique, sans doute ici burgonde. L'ager Saviniacensis, connu dans le cartulaire de l'abbaye par une trentaine de mentions qui s'échelonnent entre la fin $d u \mathrm{IX}^{\mathrm{e}}$ et le début $\mathrm{du} \mathrm{XI}^{\mathrm{e}}$ siècle, débordait sur plusieurs paroisses avoisinantes et comportait vingt-quatre villae. La plupart d'entre elles échappent à l'identification, mais leurs noms témoignent en général de leur ancienneté : Arciacus [Arcy, c. Sourcieux], Bisboch [Bibost], Bretonica, Burbuniacus, Calmis, Celsiacus [Sourcieux], Chivinnacus [Chevinay], Domariacus [c. Bessenay], Felix Vulpis, Fontanillas, Grisiniacus/Chrisigniacus [Grésigny, c. Saint-Pierre-la-Palud], Ischiriacus, Longavilla, Luans [Louhans, c. L'Arbresle], Malavabra, Mauriacus, Monasteriolus, Pugniacus [Pugny, c. Saint-Pierre-la-Palud], Samarciacus, Savinisetus, Tasliacus, Taxelanus [Taylan, c. Savigny], Toroniacus [Thorigny, c. Bibost] et Vitcellis.

L'existence même d'un ager Saviniacensis, aussi tardive que soit sa première attestation textuelle ${ }^{36}$, témoigne d'une structuration du territoire, autour d'une villa éponyme, nettement antérieure à la fondation supposée de l'abbaye. L'ager est une subdivision du pagus propre à certaines régions qui s'étendent de la Bourgogne aux Alpes et à la vallée du Rhône. C'est une entité encore difficile à cerner, en dépit des nombreuses études dont il a fait l'objet ${ }^{37}$. Les incertitudes qui l'entourent tiennent au fait que l'ager - ou l'aicis, son équivalent dans le Massif central voisin (Auvergne et Limousin notamment) - est surtout connu par des textes de l'époque carolingienne ( $\left(\mathrm{X}^{\mathrm{e}}-\mathrm{X}^{\mathrm{e}}\right.$ siècle), qui abondent dans les décennies précédant sa disparition ( $1^{\mathrm{re}}$ moitié $\mathrm{du} \mathrm{XI}^{\mathrm{e}}$ siècle), alors qu'il s'agit d'une structure ancienne, presque déjà anachronique. À partir de l'exemple du Mâconnais, privilégié sur le plan documentaire, François Bange a montré que les agri forment au $\mathrm{x}^{\mathrm{e}}$ siècle un réseau profondément enraciné que les vicariae ne parviennent pas à supplanter, et l'auteur déduit de cette concurrence difficile pour les secondes une origine « nettement pré-carolingienne » des premiers ${ }^{38}$.

Quel type d'établissement pourrait être suffisamment important pour justifier la transmission de son toponyme à l'abbaye? Plusieurs pistes de réflexion sont envisageables, depuis la villa aristocratique jusqu'au domaine public impérial. Le Liber cartarum mentionne d'ailleurs plusieurs localités voisines de Savigny comme d'anciennes terrae fiscales. C'est le cas par exemple d'une terre, citée dans un acte de la seconde moitié du $\mathrm{x}^{\mathrm{e}}$ siècle, qui est située in villa Bretonica, in agro Saviniacensis ${ }^{39}$. La présence de ces fiscs en Lyonnais ne permet cependant pas de tirer la moindre conclusion sur le cas savinien. L'absence de tout autre élément d'information ne permet pas de se prononcer sur la nature de cet établissement potentiellement antérieur à l'abbaye de Savigny. Mais que ses origines soient fiscales ou simplement aristocratiques, tardo-antiques ou mérovingiennes, ne changent guère les conclusions relatives à l'abbaye, qui semble bien aménagée sur un site antérieurement occupé.

Une dernière hypothèse mérite en revanche d'être formulée au sujet de la villa de Savigny, qui, au contraire de l'ager Saviniacensis, est curieusement absente du cartulaire. Les premières mentions du bourg savinien remontent seulement au milieu du XI $\mathrm{e}^{\mathrm{e}}$ siècle. Faut-il pour autant en déduire que la création du bourg monastique est aussi tardive ? Les chartes du Liber cartarum rappellent les acquisitions de terres faites par les moines $\mathrm{au} \mathrm{x}^{\mathrm{e}}$ et au XI ${ }^{\mathrm{e}}$ siècle ; à en croire l'absence de mention d'une villa savinienne, l'abbaye n'a donc pas reçu de terres sises à Savigny même au cours de ces deux siècles. Peut-être les a-t-elle reçues en amont de cette période faste, à une époque dénuée de toute 
documentation archivistique (avant 935), peut-être même au moment de la fondation du monastère?

Si l'exemple de Cluny, qui réunit Guillaume d'Aquitaine et Bernon, demeure sans doute le mieux connu, la donation d'un domaine par un riche laïc à un homme d'Église, pour créer une maison de religieux, n'est certainement pas un cas de figure isolé au Moyen Âge. La réutilisation de bâtiments existants pourrait en outre faciliter, sur un plan pratique, l'installation de nouvelles communautés monastiques et assurer leur succès. Cette aura qui entoure, depuis le xvIII ${ }^{e}$ siècle, la petite chapelle Saint-Léger, sur fond d'ancienneté mémorable, n'est peut-être pas qu'une élucubration érudite! L'analyse archéologique de ce petit monument, qui fait malheureusement toujours défaut à ce jour, pourrait apporter quelques surprises...

\section{NOTES}

1. M. RUBELLIN, Église et société chrétienne d'Agobard à Valdès, Lyon, 2003.

2. Sur cette question, voir les travaux précurseurs de Pierre-Roger Gaussin : P.-R. GAUSSIN, « De la seigneurie rurale à la baronnie : l'abbaye de Savigny en Lyonnais ", Le Moyen Âge, 1-2 (1955) ; ID., L'influence des abbayes bénédictines, fasc. 1 (Les dépendances de l'abbaye Saint-Martin de Savigny), 1955. Pierre Ganivet, François Demotz et Christian Gensbeitel reprennent cette question dans le cadre du PCR.

3. O. PUEL, Saint-Martin de Savigny: archéologie d'un monastère lyonnais. Histoire monumentale et organisation spatiale des édifices cultuels et conventuels (IX ${ }^{e}-\mathrm{XIII}{ }^{e}$ siècle), 2013, p. 720-745 [en ligne : https://halshs.archives-ouvertes.fr/tel-01243383/].

4. Un PCR consacré à l'abbaye de Savigny et à ses territoires a également été mené, sous la direction d'olivia Puel et Pierre Ganivet, entre 2009 et 2013, avec le soutien du Service régional de l'archéologie Rhône-Alpes et de l'université Lumière-Lyon 2. Une monographie est à l'étude pour concrétiser ces travaux.

5. Si le prologue du Livre de chartes, rédigé à la demande de l'abbé Ponce vers 1135, rend les Hongrois responsables de la crise que l'abbaye de Savigny traverse au $\mathrm{x}^{\mathrm{e}}$ siècle, il faut néanmoins souligner que les textes contemporains des événements supposés sont beaucoup plus nuancés et que l'église Sainte-Marie, dont les vestiges les plus anciens pourraient remonter au IX $\mathrm{I}^{\mathrm{e}}$ siècle, ne porte aucune trace de destruction violente. Sur cette question, voir les travaux récents d'Hervé Mouillebouche: H. MouilLEBouche, « Les Hongrois en Bourgogne : le succès d'un mythe historiographique ", Annales de Bourgogne, 78/2 (2006), p. 126-168. Voir aussi les travaux menés dans le cadre du PCR par les auteurs : P. GANIVET, «L'abbaye de Savigny au Moyen Âge : quelques questions d'histoire ", in O. PUEL, Compte rendu du séminaire "L'abbaye de Savigny", 2006, p. 4-26 et O. PUEL, Saint-Martin de Savigny..., op. cit., p. 52 à 54.

6. A. BERNARD, Cartulaire de l'abbaye de Savigny (suivi du Petit cartulaire de l'abbaye d'Ainay), t. 1 (Cartulaire de Savigny), Paris, 1853.

7. O. FAURE-BRAC, Carte archéologique de la Gaule, Le Rhône, t. 69/1, Paris, 2006, p. 513.

8. O. PUEL, Saint-Martin de Savigny..., op. cit., p. 509-511.

9. Voir en particulier J.-B. MONTFALCON, Histoire de Lyon, Lyon, 1851, p. 225.

10. A. BERNARD, Cartulaire..., op. cit., p. LXXV. 
11. L'église romane, commencée sous l'abbé Dalmace, dans la seconde moitié du $\mathrm{xI}^{\mathrm{e}}$ siècle, est construite autour de l'église carolingienne qui est quant à elle démolie progressivement, au fur et à mesure de l'avancée des travaux. O. PUEL, Saint-Martin de Savigny..., op. cit., p. 732-742.

12. A. BERNARD, Cartulaire..., op. cit., p. LXXVI-LXXVII.

13. L'histoire de l'abbaye de Cluny offre un exemple similaire, étudié par Dominique Iogna-Prat puis Isabelle Rosé. Si la tradition médiévale associe Odon (926/927-942), Maïeul (954-994), Odilon (994-1049) et Hugues de Semur (1049-1109) aux origines du monastère, l'historiographie clunisienne élaborée sous l'abbatiat d'Odilon retient essentiellement Maïeul. Odon est le grand absent des cartulaires de l'abbaye ou du Liber tramitis aevi Odilonis. L'explication de ce phénomène tient sans doute à la personnalité et à l'action des deux abbés considérés. Pour les moines clunisiens de l'an Mil, Odon est le réformateur discret, celui qui «a probablement passé son existence à voyager d'un endroit à un autre [pour introduire dans les établissements ainsi visités une nouvelle forme de vie monastique], sans se fixer véritablement nulle part». Il n'est pas le chef charismatique nécessaire pour l'abbaye au moment de la formation de l'Ecclesia cluniacensis. Maïeul, qui ramène à Cluny les reliques des saints Pierre et Paul en 981, répond davantage aux critères recherchés. Il représente à la fois la stabilité du gouvernement abbatial et le lien spécifique qui unissait Cluny à Rome. Il incarne parfaitement l'abbé-modèle, l'abbé-saint d'ailleurs reconnu par la bulle d'exemption accordée en 998 -, dont Cluny avait alors besoin pour légitimer son ascension fulgurante et assurer sa longévité. D. IOGNA-PRAT, "Panorama de l'hagiographie abbatiale clunisienne ", in ID., Études clunisiennes, 2002, p. 35-73 ; I. Rosé, Construire une société seigneuriale. Itinéraire et ecclésiologie de l'abbé Odon de Cluny (fin $d u I^{e}$-milieu $d u X^{e}$ siècle), Turnhout, 2008.

14. P. GEARY, Le vol des reliques au Moyen Âge, Paris, 1993, p. 102-114.

15. D.-O. HUREL, "Cluny et le monachisme bénédictin moderne », in N. STRATFORD (dir.), Cluny, 910-2010. Onze siècles de rayonnement, Paris, 2010, p. 64-73.

16. Dans son analyse des statuts publiés par François I d'Albon en 1493, Jean Roux conclut ses commentaires pessimistes en ses termes : "Cette réforme de l'abbaye suffit à elle seule pour illustrer la gestion de François [I] d'Albon, mais ce fut pour l'ordre comme un dernier effort qui annonçait sa fin prochaine. L'air qu'il respirait se chargeait tous les jours de vapeurs empoisonnées... » J. Roux, "Savigny et son abbaye », in L. BoITEL (dir.), Album du Lyonnais. Villes, bourgs, villages, églises et châteaux du département du Rhône, 1844, p. 186.

17. PARIS, Bibliothèque nationale de France, lat. 10036, fol. $7 \mathrm{v}^{\circ}$.

18. G. C. DE NEUfBouRG, "La plus ancienne rédaction du prétendu cartulaire de Savigny ", in Chartes du Forez, t. 18/1, 1966, p. 19.

19. Citation extraite des Nomina abbatum: G. C. DE NEUFBOURG, «La plus ancienne rédaction... », ibid., p. 27.

20. Archives départementales du Rhône, 1 H 24/1-2.

21. Gallia Christiana, 1876, col. 269-279.

22. En rouvrant le dossier de l'île-désert de Lérins à l'aune des problématiques actuelles, Rosa Maria Dessi et Michel Lauwers ont, par exemple, mis en évidence le caractère hautement symbolique de cet isolement supposé qui permet à Eucher, à Fauste et à bien d'autres encore, d'amplifier considérablement le mérite des premiers moines. Contrairement à la vision réductrice de Laurent de Foudras, le terme de solitudo ne se résume pas à cette seule acception au Moyen Âge: d'après Gabriel de Carvalho Godoy Castanho, il possède en effet une triple signification sentimentale, spatiale et ascétique. Bien plus que l'éloignement réel de toute vie humaine, c'est alors la clôture monastique qui permet aux moines de trouver, dans le cloître, un lieu où ils peuvent s'isoler dans le silence. De fait, la notion de "désert " devient un topos littéraire, qui amplifie le mérite des moines fondateurs, plutôt qu'une réalité empirique, et que les érudits $\mathrm{du} \mathrm{XIX}^{\mathrm{e}}$ siècle reprendront abondamment. Dans son travail de synthèse sur les 
implantations monastiques en Europe occidentale, du IV siècle à l'époque carolingienne, Gilles Rollier aboutit d'ailleurs à cette même conclusion, aujourd'hui admise : l'idéal symbolique n'est pas un facteur déterminant pour le choix concret d'un site d'implantation. R. M. DESSI et M. LAUWERS, «Désert, église, île sainte. Lérins et la sanctification des îles monastiques de l'Antiquité à la fin du Moyen Âge ", in Y. CODOU et M. LAUWERS, Lérins, une île sainte de l'Antiquité au Moyen Âge, Turnhout, 2009, p. 231-279; G. DE CARVALHO GODOY, «Le lieu de la solitudo au XII siècle : réflexions autour du cas chartreux ", Bucema, 14/1 (2010), p. 253-260 ; G. ROLLIER, Implantation et hydraulique monastique : le cas de Cluny, thèse d'archéologie médiévale, université Lumière-Lyon 2 , 2010.

23. Texte édité : voir MGH, Cap. I, p. 349-352 ; Corpus Consuetudinum Monasticorum, I, Siegburg, 1963, p. 496.

24. M. RUBELLIN, "L'abbaye de Savigny en Lyonnais au Moyen Âge ", in M. RUBELLIN, Église et société..., op. cit., p. 301-302.

25. Si les datations proposées par Auguste Bernard doivent être considérées avec prudence, comme l'a déjà souligné Édouard Perroy à propos des chartes du Forez [É. PERROY, « Notes sur la chronologie des chartes de Savigny », Bulletin de la Diana, 28 (1943), p. 202-211], l'authenticité des actes retranscrits dans ce cartulaire ne doit cependant pas être mise en doute.

26. A. BERNARD, Cartulaire..., op. cit., ch. $\mathrm{n}^{\circ} 16$. L'acte porte la souscription de trois moines: Burgulinus, Sentfredus et Gotfredus. Il est daté sub die tertia idus januarii, anno XI imperii domini nostri Ludovici. Bernard datait : «11 Jan. 825 ? », mais on est tenté, de prime abord, de le rattacher à la série des actes contemporains de l'empereur Louis III de Provence (901-928) et de proposer la date de 912 , le couronnement impérial de Louis ayant eu lieu en février. Néanmoins, aucun des personnages mentionnés n'apparaît dans ces actes du début du $\mathrm{x}^{\mathrm{e}}$ siècle, notamment aucun des trois moines souscripteurs, en dépit des nombreuses souscriptions monastiques que fournissent les précaires de cette époque. Un rapprochement avec les chartes $n^{\circ} 22$ de 911 (David abbé) et $\mathrm{n}^{\circ} 17$ de 913 (Étienne abbé) semble particulièrement éclairant : ces deux textes comportent les souscriptions de trois autres moines (David, Beroldus et Aimo) qui figureraient très vraisemblablement dans l'acte étudié, si celui-ci était de 912 . En revanche, la charte $n^{\circ} 18$ (in mense julio, anno XVIII regni Ludovici imperatoris) ne peut être de juillet 832 : l'abbé Asterus est identique à l'abbé Austerius mentionné en 906 (A. BERNARD, Cartulaire..., ibid., ch. n 15 : les moines témoins apparaissent dans d'autres actes du début du $\mathrm{x}^{\mathrm{e}}$ siècle).

27. Ager non identifié. Voir A. BERNARD, Cartulaire..., ibid., ch. $\mathrm{n}^{\circ} 369$.

28. Sur le rapport de Leidrade, voir: A. CoviLle, Recherches sur l'histoire de Lyon du ve siècle au IX siècle (450-800), Paris, 1928, p. 268 sqq.

29. M. AUBRUN, L'ancien diocèse de Limoges des origines au milieu du XI esiècle, Clermont-Ferrand, 1981, p. 276.

30. Voir, en ce sens, les prudentes observations de Michel Rubellin : M. RUBELLIN, «L'abbaye de Savigny... », op. cit., p. 302.

31. P. R. GAUSSIN, L'influence des abbayes..., op. cit., p. 140.

32. M. RUBELLIN, « L'abbaye de Savigny... », op. cit., p. 302.

33. MGH, D. Kar. III, ch. $n^{\circ} 123$. Voir aussi A. BERNARD, Cartulaire..., op. cit., ch. $\mathrm{n}^{\circ} 960$ : (...) cenobium cum suis omnibus ad illud pertinentibus in honore domini nostri Jesu Christi sub invocatione beatissimi Martini episcopi et confessoris constructum, quod Saveniacus publice vocatur.

34. P. GANIVET, «L'ager Saviniacensis: premières remarques", in O. PUEL (dir.), PCR Savigny: l'abbaye et son territoire, rapport intermédiaire, Service régional de l'Archéologie Rhône-Alpes, 2009, p. 40-56, ici p. 43.

35. http://www.inrap.fr/une-ferme-antique-fleurieux-sur-l-arbresle-4261

36. A. BERNARD, Cartulaire..., op. cit., ch. $\mathrm{n}^{\circ} 2$ (886). 
37. Parmi les principales, et les plus anciennes, il faut citer notamment celle d'A. BERNARD, "Nomenclature des subdivisions territoriales des diocèses de Lyon et de Mâcon, et des pays circonvoisins, aux IX ${ }^{\mathrm{e}}$, $\mathrm{X}^{\mathrm{e}}$ et $\mathrm{XI}^{\mathrm{e}}$ siècles ", in A. BERNARD, Cartulaire..., ibid., t. 2, p. 1069 sqq.

38. F. BANGE, «L'ager et la villa: structures du paysage et du peuplement dans la région mâconnaise à la fin du haut Moyen Âge (IX ${ }^{\mathrm{e}}-\mathrm{XI}^{\mathrm{e}}$ siècle) ", Annales ESC, 1984, p. 529-569, ici p. 553.

39. A. BERNARD, Cartulaire..., op. cit., ch. $\mathrm{n}^{\circ} 104$, p. 75-76.

\section{AUTEURS}

\section{OLIVIA PUEL}

Chercheure associée UMR 5138

\section{PIERRE GANIVET}

Maître de conférences université Clermont Auvergne 